\title{
REVIEW
}

\section{Cognitive function in COPD}

\author{
J.W. Dodd, S.V. Getov and P.W. Jones
}

\begin{abstract}
In order to characterise the overall clinical picture of chronic obstructive pulmonary disease (COPD) a better understanding of all relevant comorbidities is required. It is increasingly recognised that COPD is a multi-component disease, but little attention has been paid to its effects on cognitive function.

Cognitive dysfunction is associated with increased mortality and disability; however, it remains poorly understood in COPD. This review examines mechanisms of injury and dysfunction to the brain and considers the methods used to evaluate cognition, and assembles evidence concerning the nature and level of cognitive impairment in COPD.

Our main findings are: 1) there may be a pattern of cognitive dysfunction specific to COPD; 2) cognitive function is only mildly impaired in patients without hypoxaemia; 3) the incidence of cognitive dysfunction is higher in hypoxaemia; 4) hypoxaemia, hypercapnia, smoking and comorbidities (such as vascular disease) are unlikely to account for all of the cognitive dysfunction seen in COPD; 5) there is weak or no association between cognitive function and mood, fatigue or health status; 6) cognitive dysfunction may be associated with increased mortality and disability; and 7) there is limited evidence for a significant effect of treatment on cognitive function.
\end{abstract}

KEYWORDS: Brain, chronic obstructive pulmonary disease, cognitive function, comorbidities, neuropsychological test

hronic obstructive pulmonary disease (COPD) is frequently associated with comorbidities, such as cardiovascular disease, anaemia and osteoporosis, leading to the widely accepted view that COPD is a complex multi-component disorder, which is associated with a wide range of psychological and social problems [1]. Measures of disease severity, such as airflow limitation, are poor markers of relevant patient outcomes, largely because they do not reflect the multi-system nature of the disease. Therefore, identification, understanding and assessment of all relevant comorbidities in COPD is needed to better characterise the full clinical spectrum of the disease [2]; cognitive impairment is one such proposed comorbidity.

It is reasonable to regard patients with COPD to be at increased risk of neuronal injury, either through factors related to COPD such as hypoxaemia, or as a result of comorbidities which adversely affect the brain such as vascular disease and smoking (fig. 1).

Cognitive impairment has been demonstrated in $77 \%$ of patients with COPD and hypoxaemia [3].
Furthermore, it has been suggested that impaired performance in neuropsychological tests may be a predictor of mortality and disability in certain COPD populations [4-6]. However, despite their potential importance, understanding of cognitive problems in COPD remains incomplete.

\section{COGNITION: DEFINITIONS AND CONCEPTUAL FRAMEWORKS}

Cognition is a collective term for high-order neural processes that underpin information handling. These have been variously sub-classified according to conceptual frameworks such as those shown (table 1). In practice, cognitive abilities are mainly inferred from behaviour, which itself is determined by a wide variety of neurological, psychological and emotional factors [7]. The relationships between the many processes involved in an everyday cognitive task are complex, but cognitive ability is usually broken up into discrete domains, although it is rarely possible to study single domains in isolation.

Dementia is defined by the development of multiple cognitive deficits with memory impairment and one or more other cognitive disturbance(s)
AFFILIATIONS

Cardiac and Vascular Medicine St George's University of London, London, UK.

CORRESPONDENCE

J.W. Dodd

Respiratory Medicine, Cardiac and Vascular Sciences

St George's University of London

Cranmer Terrace

London

SW17 ORE

UK

E-mail: jdodd@sgul.ac.uk

Received:

Aug 052009

Accepted after revision:

Sept 262009 


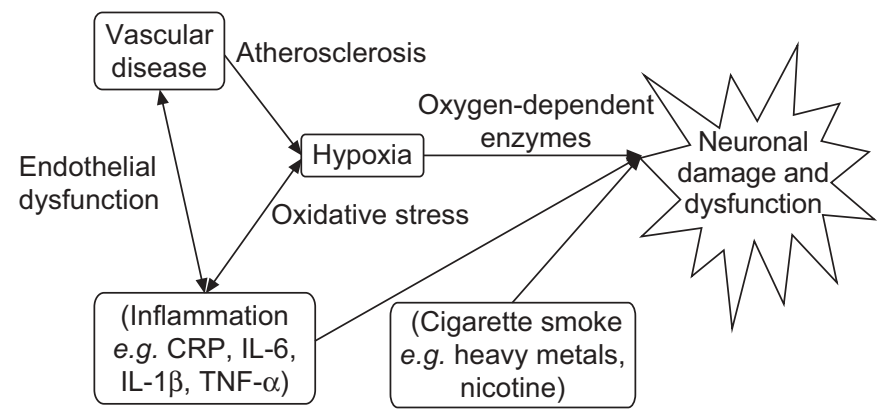

FIGURE 1. Possible mechanisms contributing to neuronal damage in chronic obstructive pulmonary disease. CRP: C-reactive protein; IL: interleukin; TNF: tumour necrosis factor.

that cause significant impairment in social and occupational functioning [8].

Neuropsychological tests aim to provide standardised and objective measurement of the functioning of one or more specific cognitive domains. Performance within each domain depends on one or more of the main classes of cognitive function. The tasks performed as part of neuropsychological testing often closely resemble mental challenges encountered in everyday life.

\section{MECHANISMS OF COGNITIVE IMPAIRMENT}

A key mechanism proposed for cognitive dysfunction in COPD is neuronal damage mediated through hypoxia, but it has also been suggested that oxygen-dependant enzymes which are important in the synthesis of neurotransmitters, such as acetylcholine, may be affected [9]. A magnetic resonance spectroscopy study in patients with non-hypoxic severe COPD showed that cerebral metabolism was significantly altered and that the pattern of derangement differed from that seen in heart failure and diabetes [10].

Inflammation may play a role, since there is evidence that $\mathrm{C}$-reactive protein may be associated with cognitive decline, either through a direct neurotoxic effect [11] or an effect on cerebral atherosclerosis. Other inflammatory mediators have also been linked to cognitive dysfunction, including interleukin (IL)-6, IL-1 $\beta$, tumour necrosis factor- $\alpha$ and $\alpha_{1}$-antichymotrypsin [12, 13]. However, these studies suggest an association rather than a causal link [14].

\section{IS THERE EVIDENCE OF COGNITIVE DYSFUNCTION IN COPD?}

The majority of studies have shown that patients with COPD have significant cognitive impairment, either globally or in domains such as perception, memory and motor functions (table 2). In the nocturnal oxygen therapy (NOTT) trial, $42 \%$ of patients with COPD had moderate-to-severe cognitive impairment compared with $14 \%$ amongst controls [3]. In a follow-up of the same cohort, the rate of neuropsychological deficit rose from $27 \%$ in mild hypoxaemia to $62 \%$ in severe hypoxaemia [31]. In addition, severe COPD cognitive impairment has been reported to worsen over time [32].

However, cognitive impairment in COPD is not always reported. In one study, patients with mild hypoxaemia had worse verbal fluency compared with a control group but, they were still within the normal range [28]. In another study, no

\begin{tabular}{|c|c|c|}
\hline ABLE 1 & $\begin{array}{l}\text { gnitive domains and their re } \\
\text { gnitive functions tested in pr }\end{array}$ & $\begin{array}{l}\text { ationship to } \\
\text { actice }\end{array}$ \\
\hline $\begin{array}{l}\text { Cognitive } \\
\text { domain }\end{array}$ & Description & $\begin{array}{l}\text { Cognitive } \\
\text { functions }\end{array}$ \\
\hline \multirow[t]{2}{*}{ Receptive } & $\begin{array}{l}\text { Complex sensory reception: central } \\
\text { analysis, integration and encoding } \\
\text { of stimuli }\end{array}$ & Perception \\
\hline & $\begin{array}{l}\text { Perception: integration of sensory } \\
\text { information into psychologically } \\
\text { meaningful constructs, including } \\
\text { recognition, discrimination and } \\
\text { orientation }\end{array}$ & Construction \\
\hline \multirow[t]{2}{*}{$\begin{array}{l}\text { Learning and } \\
\text { memory }\end{array}$} & $\begin{array}{l}\text { Implicit (non-declarative) memory: } \\
\text { memory of skills and perceptual } \\
\text { learning }\end{array}$ & Memory and learning \\
\hline & $\begin{array}{l}\text { Declarative memory: relating to } \\
\text { information, objects and events }\end{array}$ & Verbal/language \\
\hline Processing & $\begin{array}{l}\text { The ability to relate two or more } \\
\text { pieces of information. Includes } \\
\text { computation, reasoning, concept } \\
\text { formation, abstraction, } \\
\text { organisation, planning and } \\
\text { problem solving }\end{array}$ & $\begin{array}{l}\text { Memory and learning } \\
\text { Verbal/language } \\
\text { Reasoning } \\
\text { Executive function }\end{array}$ \\
\hline $\begin{array}{c}\text { Expressive } \\
\text { function }\end{array}$ & $\begin{array}{l}\text { The physical expression of cognitive } \\
\text { processes (verbal, writing and } \\
\text { drawing, manipulation, gestures } \\
\text { and movements) }\end{array}$ & $\begin{array}{l}\text { Construction } \\
\text { Reasoning } \\
\text { Executive function } \\
\text { Motor function }\end{array}$ \\
\hline $\begin{array}{l}\text { Mental activity } \\
\text { variables }\end{array}$ & $\begin{array}{l}\text { Attention and consciousness. Not } \\
\text { classes of cognition per se. } \\
\text { Facilitate cognitive processes }\end{array}$ & $\begin{array}{l}\text { Perception } \\
\text { Memory and learning } \\
\text { Construction } \\
\text { Reasoning } \\
\text { Executive function } \\
\text { Motor function } \\
\text { Processing speed }\end{array}$ \\
\hline
\end{tabular}

It is important to note that no classification of sub-divisions and domains of cognition is universally accepted; the one presented here is one of many.

difference in mini mental state examination (MMSE) was reported between community-based COPD patients and a healthy group, although the COPD group may have also included cases of asthma [33].

\section{FACTORS INFLUENCING COGNITIVE FUNCTION IN COPD}

Age and educational level are demographic variables that are thought to strongly relate to neuropsychological performance in all populations [7]. Figure 2 summarises the factors thought to be important in influencing the development of cognitive impairment in both COPD patients and healthy individuals. It shows that, although many factors are shared by both groups, many congregate more frequently within COPD. The influence of each of these factors will be discussed briefly later in the review.

\section{COGNITIVE PERFORMANCE AND LUNG FUNCTION}

The association between lung function and cognitive function has been tested in a number of studies in large healthy 


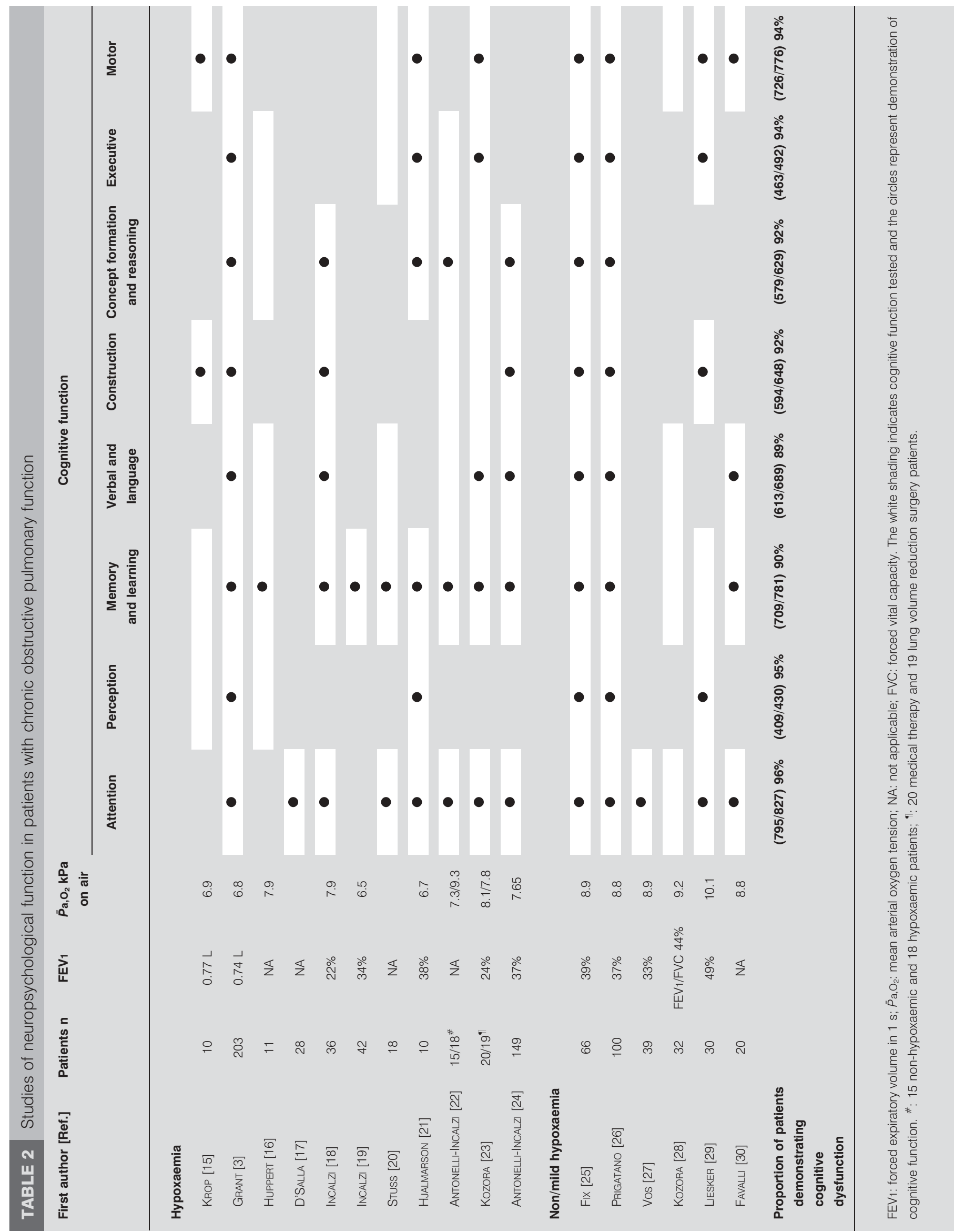




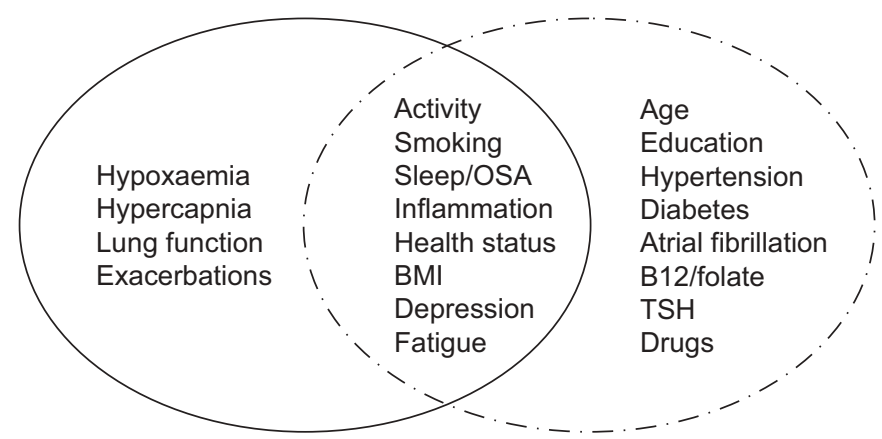

FIGURE 2. Potential factors thought to effect cognitive function in chronic obstructive pulmonary disease. OSA: obstructive sleep apnoea; BMl: body mass index; TSH: thyroid stimulating hormone. — : chronic obstructive pulmonary disease; $\cdot-\cdot \cdot \cdot-\cdot$ general population.

populations, particularly in elderly groups, but the correlations were often weak and confounders were not always adjusted for (table 3). It has been suggested that lung function is actually a marker of physical activity, which itself may account for any associations with cognitive status [41]. Studies investigating the relationship between lung function and cognition in COPD populations have shown even less consistent results, suggesting that lung function is not a reliable predictor of cognitive function in this group (table 4).

\section{COGNITIVE FUNCTION AND HYPOXAEMIA}

Table 1 summarises studies of cognitive function and hypoxaemia in COPD, the larger studies suggest global impairment across cognitive domains with the most severe deficits in perception and motor function [3, 25, 26]. Although the majority of studies assessed patients with hypoxaemia, deficits have also been found in non-hypoxaemic patients $[29,30]$. It is difficult to draw clear conclusions by comparing these studies, due to differences in disease severity and test methodologies used. The definition of hypoxaemic COPD also varied between studies. However, attention deficits and problems with memory executive and motor functions appear to be common. Perception and language difficulties appear to be less frequently reported.

\section{Correlations between cognitive functions and degree of hypoxaemia}

The correlation between cognitive function and arterial oxygen tension $\left(\mathrm{Pa}_{1} \mathrm{O}_{2}\right)$ is weak $(\mathrm{r} \sim 0.2)[3,26]$ and oxygen saturation contributed to just $5 \%$ of predicted variance in clinician judged global cognitive performance [3]. These observations from the NOTT and Intermittent Positive Pressure Breathing (IPPB) studies contrast with those from an earlier small study in which $\mathrm{Pa}_{1} \mathrm{O}_{2}$ correlated with attention, motor function and processing speed $\left(\mathrm{r}^{2}=0.63\right)$ [25]. Another study reported that memory was correlated to $\mathrm{Pa}, \mathrm{O}_{2}$, but language and perception were not [20]. Nadir nocturnal $\mathrm{Pa}_{2} \mathrm{O}_{2}$ has been shown to

\section{TABLE 3 Lung function and cognition in healthy populations}

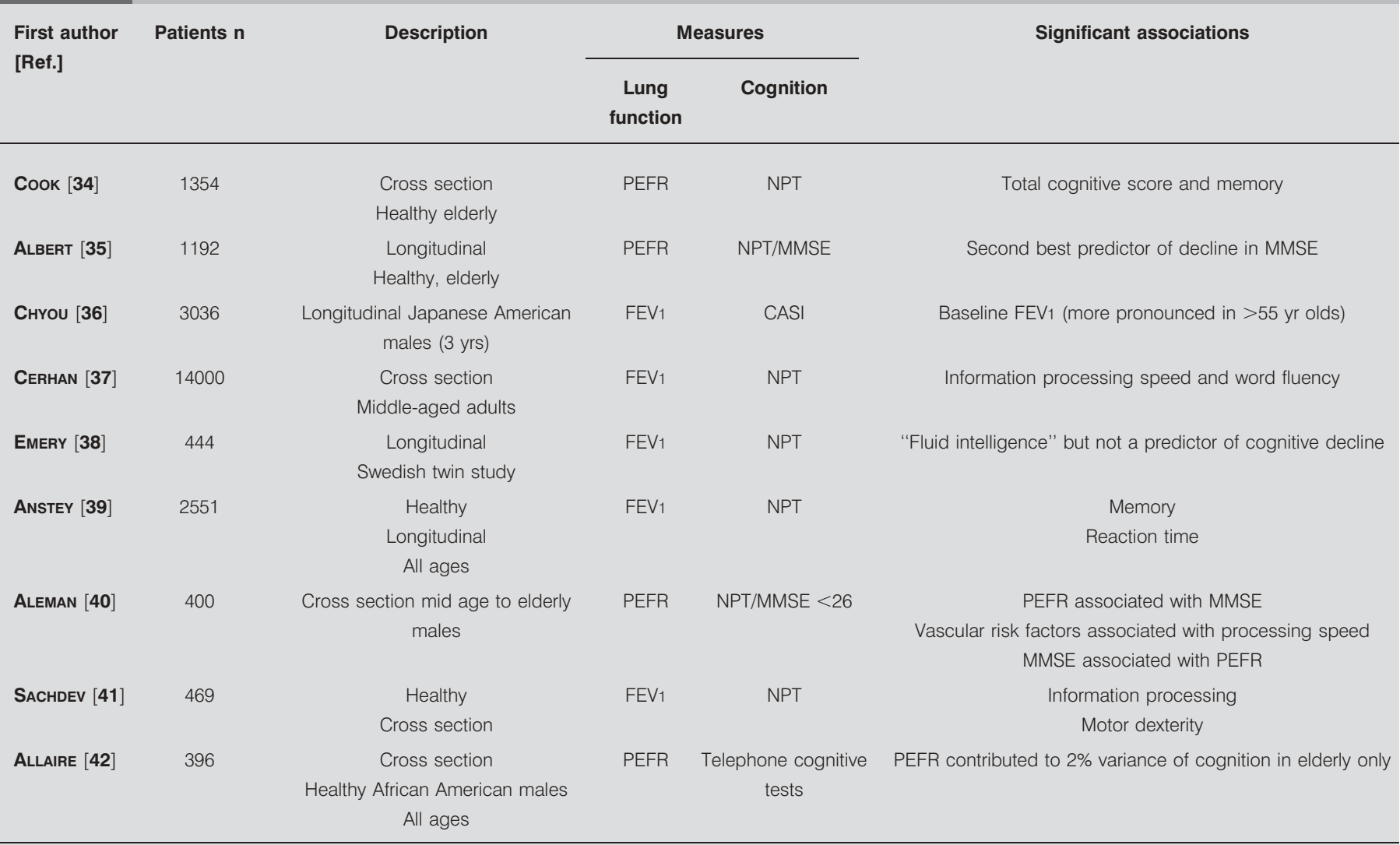

PEFR: peak expiratory flow rate; NPT: formal neuropsychological testing; MMSE: mini mental score examination; FEV1: forced expiratory volume in 1 s; CASI: cognitive ability screening instrument. 
TABLE 4 Lung function and cognition in chronic obstructive pulmonary disease (COPD) patients

\begin{tabular}{|c|c|c|c|c|c|}
\hline First author [Ref.] & Patients n & Description & Lung function & Cognition & Correlations \\
\hline FIx [25] & 66 & $\begin{array}{l}\text { Longitudinal } \\
\text { Hypoxic COPD }\end{array}$ & FEV 1 & NPT & $\begin{array}{l}\text { Attention, vis-motor and } \\
\text { perception }\end{array}$ \\
\hline GRANT [3] & 203 & $\begin{array}{c}\text { Case control } \\
\text { Hypoxaemic COPD }\end{array}$ & FEV 1 & NPT & Nil \\
\hline INCALZI [43] & 84 & Prospective COPD & FEV 1 & MMSE & $\begin{array}{l}\text { Decline in MMSE } \\
\text { worse in severe airflow obstruction }\end{array}$ \\
\hline KozORA [28] & 32 & Mildly hypoxic COPD & Full PFT & NPT & Nil \\
\hline EtNier [44] & 98 & $\begin{array}{l}\text { Older COPD mild disease } \\
\text { and hypoxia }\end{array}$ & Full PFT & NPT & $\begin{array}{l}\text { FVC associated with working } \\
\text { memory } \\
6 \mathrm{MWT} \text { associated with fluid } \\
\text { intelligence and processing } \\
\text { speed }\end{array}$ \\
\hline ANTONELLI-INCALZI [45] & 381 & $\begin{array}{l}\text { COPD } \\
\text { Elderly }\end{array}$ & GOLD stage & NPT/MMSE & Nil \\
\hline LIESKER [29] & 30 & $\begin{array}{c}\text { Non-hypoxaemic } \\
\text { COPD } \\
\text { Case control }\end{array}$ & FEV 1 & NPT & Nil \\
\hline ОнRиі [46] & 135 & $\begin{array}{l}\text { Respiratory failure on LTOT versus } \\
\text { healthy cross section }\end{array}$ & FEV 1 & MMSE & Nil \\
\hline
\end{tabular}

FEV1: forced expiratory volume in $1 \mathrm{~s}$; NPT: neuropsychological tests; IPPB: intermittent positive pressure breathing; MMSE: mini mental score examination; PFT: pulmonary function tests; FVC: forced vital capacity; 6MWT: 6-min walk test; GOLD: Global Initiative for Chronic Obstructive Lung Disease; LTOT: Iong-term oxygen therapy.

correlate with attention, but it is not clear if co-existent obstructive sleep apnoea (OSA) had been excluded [27].

In summary, the exact relationship between cognitive impairment and hypoxaemia remains unclear. Whilst a number of studies have shown a clear association between hypoxaemia and poor cognitive performance, this has been inconsistent and correlations have been weak. There are also inconsistencies as to whether patients with early disease and mild hypoxaemia have significantly impaired cognition. Current evidence would suggest that hypoxaemia alone is not enough to entirely account for the cognitive deficits seen in COPD.

\section{COGNITIVE FUNCTION AND HYPERCAPNIA}

Studies have reported a variable correlation between arterial carbon dioxide tension $\left(\mathrm{Pa}_{\mathrm{a}} \mathrm{CO}_{2}\right)$ and cognitive function. In patients with hypercapnic respiratory failure, $\mathrm{Pa}, \mathrm{CO}_{2}$ correlated with memory, complex attention and information processing speed, but not with language, motor function and simple attention [19]. INCALZI et al. [18] suggested that $\mathrm{Pa}_{\mathrm{a}} \mathrm{CO}_{2}$ was related to verbal memory and attainment and, in a study of patients awaiting lung transplantation, lower $\mathrm{Pa}_{1}, \mathrm{CO}_{2}$ was significantly correlated to better measures of executive function, attention and verbal memory [47]. In contrast, there was no correlation between cognitive function and hypercapnia in the NOTT and IPPB studies or in studies by GRANT et al. [31] and FIX et al. [25]. Overall the relationship between $\mathrm{Pa}_{1}, \mathrm{CO}_{2}$ and cognitive impairment is even less clear than that for $\mathrm{Pa}_{\mathrm{a}} \mathrm{O}_{2}$.

\section{EFFECTS OF COPD EXACERBATIONS ON COGNITIVE FUNCTION}

Only three studies have directly addressed the impact of exacerbations on cognitive function. In elderly patients admitted with a non-acidotic exacerbation of COPD, MMSE scores were low but unrelated to 6-month mortality [48]. In another study using the MMSE in patients who required mechanical ventilation during the exacerbation, there was significantly impaired cognitive function at the time of discharge, but this had recovered substantially by 6 months [49]. The P300 is an electrophysiological test used as a surrogate marker of information processing, attention and intellect memory [50]. During an exacerbation, COPD patients were reported to have impaired information processing and a tendency to worse attention and memory [51]. It appears that cognitive function is impaired during exacerbation, but may recover.

\section{CORRELATIONS BETWEEN ACTIVITY AND COGNITIVE FUNCTION}

A number of studies have shown that physical activity is associated with both the maintenance and improvement in cognitive function in COPD [52-58]. A case-control study of pulmonary rehabilitation showed that if visual attention, verbal memory and visuospatial functions were impaired at baseline, they improved after 3 weeks of treatment. However, practice effects were not addressed and this could have also been due to regression to the mean effect. Furthermore, the 
control group had lower exercise capacity, higher oxygen use and took their COPD medications less regularly than the treatment group [59].

Verbal fluency improved significantly with exercise in a randomised control trial of non-hypoxaemic COPD patients that compared exercise training plus education with education alone [53]. Another study showed improvement in verbal fluency after as little as $20 \mathrm{~min}$ of exercise [54]. In a group of fit patients with mild COPD, 6-min walk distance and aerobic fitness predicted $83 \%$ of the improvement in "fluid intelligence" (reasoning and problem solving) amongst COPD patients undergoing short- and long-term exercise programmes [56]. Overall there appears to be a link between exercise and cognitive function and it is important to determine whether improved exercise improves cognitive function.

\section{COGNITIVE FUNCTION IN VASCULAR DISEASE AND OTHER COMORBIDITIES}

In the general population, hypertension has been associated with a faster decline in logical reasoning and problem solving, and diabetes has been associated with accelerated decline in executive function tasks [59]. In addition, combined vascular risk factors explained a significant proportion of the variance in information processing capacity and speed, as well as general cognitive status [40]. Given that over $50 \%$ of hospitalised patients with COPD have coexistent vascular disease [60], it is likely that this will influence cognitive function. However, the pattern of cognitive dysfunction in COPD has been shown to be different to that found in multiinfarct dementia [18], and memory has been shown to be worse in subjects with chronic cerebrovascular disease than in those with COPD [61]. Therefore, it is unlikely that cognitive dysfunction in COPD is due to vascular comorbidity alone.

\section{SMOKING AND COGNITIVE FUNCTION}

In addition to the increased risk of cerebral atherosclerosis, certain particles in cigarette smoke are thought to have a direct neurotoxic effect with heavy metal constituents of smoke being linked to an increased risk of Alzheimer's disease [62, 63]. Smoking may also influence cognitive function by exacerbating cerebral hypoxia due to chronically elevated carbon monoxide causing a left shift of the oxyhaemglobin dissociation curve [3]. A multicentre European cohort showed that yearly decline in MMSE was associated with smoking status, after correcting for baseline MMSE, education and vascular events [64]. Smoking is a risk factor for pre-clinical changes detected on brain computed tomography, and longitudinal studies have found associations with middle-age smoking and cognitive dysfunction in males over a 20-yr period. Cognitive deficits associated with smoking include reduced processing speed, verbal memory and MMSE. However, whilst smoking appears to be an independent factor in cognitive dysfunction, studies have found associations between impaired lung function and cognition that are independent of current and lifetime smoking status $[41,65]$.

\section{SLEEP AND OBSTRUCTIVE SLEEP APNOEA}

Sleep is thought to be important in memory, learning, attention and tracking [31, 66]. COPD patients experience excessive daytime sleepiness and over 50\% report long sleep latency [67].
OSA occurs in $20 \%$ of individuals with COPD [68], and the conditions share a similar profile of comorbidities [69, 70]. Moderate-to-severe OSA may be associated with impaired cognitive performance, primarily vigilance and executive function with less effect on intellectual and verbal abilities [71]. However, the increase in cognitive deficit appears smaller than the increase in sleepiness [72].

Whilst the degree of cognitive impairment has been reported to be similar in COPD and OSA with shared deficits in complex reasoning, learning and memory, cognitive domains thought to be dependent on sleep, such as attention, were more impaired in OSA, whilst those thought to be affected by hypoxaemia, such as motor skills, were more impaired in COPD [73]. This observation is supported by another small study which showed that patients with severe OSA had a distinctive cognitive profile, i.e. a group-specific pattern of cognitive dysfunction compared with COPD, Alzheimer's disease and multi-infarct dementia [74].

\section{DEPRESSION}

The prevalence of depression in COPD patients ranges from $10 \%$ to $79 \%$ [15, 33, 43, 75-79]. Depressive symptoms are present in elderly people with cognitive impairment or dementia [80], but, while it is associated with impairment in executive function, memory and processing speed, it may account for only $1-2 \%$ of the variance in cognition in COPD $[8,12]$. In the NOTT trial the modest improvement in cognitive function was not associated with improvement in emotional or depressive symptoms [8].

\section{Is there a specific pattern of cognitive deficit in COPD?}

A number of studies have explored the presence of a specific pattern of neuropsychological impairment in COPD patients. Most found moderately severe deficits in areas that include attention, memory and executive function (table 1). In particular, the NOTT study suggested a global cognitive deterioration, consistent with age-related physiological decline [3]. In contrast, there is a suggestion from smaller studies that COPD patients may have a specific pattern of deterioration compared with Alzheimer's disease or multi-infarct dementia and healthy controls [18, 28].

Some of the observed heterogeneity in the deficits reported may be due to differences in severity of disease in the populations studied. For example, one study recruited hypoxaemic patients who had never had long-term oxygen [3], whereas a second studied patients who were significantly hypoxaemic and hypercapnic despite many years of oxygen therapy [18]. A third studied patients on oxygen therapy but with only very mild hypoxaemia [28]. Different neuropsychological test batteries were also used in different studies, which is an additional confounding factor. Overall, the main areas of dysfunction in COPD appear to be attention, memory, motor and executive function; this pattern may be different from that seen in Alzheimer's disease or multi-infarct dementia.

\section{Cognitive dysfunction in COPD: does it matter?}

In general population studies, cognitive dysfunction has been associated with increased length of stay, mortality, discharge destination [81], instrumental activities of daily living (IADL) [82] and the management of medicines [83]. 
Few studies have directly examined its impact in COPD. One study suggested a link between poor verbal memory and mortality [6] and, in severe COPD, impaired verbal memory was associated with poor adherence to medications [19]. Incorrect inhaler use has been associated with executive dysfunction, which affects planning and sequencing [84].

A large prospective study in COPD found no link between mortality and MMSE [48]; however, in another study, social isolation, number of medications and comorbidities were the only independent variables associated with length of stay following admission for a COPD exacerbation, not measures of cognitive function [85].

Cognitive problems have been associated with impairment in IADL in COPD [4], although in patients with mild cognitive deficit prevalence of impaired activities of daily living is low [86]. In activity-limited patients using supplementary oxygen, rate of decline in cognitive function may be related to impairment of IADL [32]. However, an earlier study did not find the same relationship [87].

In summary, cognitive dysfunction in COPD may be associated with mortality and other important patient outcomes including functional impairment; however, these associations were not consistent between studies. There appears to be no clear relationship between health status and cognitive impairment $[9,29,49,88,89]$.

\section{Assessment and treatment of cognitive impairment in COPD}

Full neuropsychological testing requires time and specialist training to perform and interpret. A simple and brief clinical assessment would be useful to screen individuals who may need further more comprehensive neuropsychological testing. Recent work suggests that the combination of an MMSE score $<24$ and dependence in at least one IADL may fulfil this role [24]. Further work is needed to determine if all patients with COPD require screening or whether it should be restricted to those who report cognitive difficulties or who have risk factors for cognitive impairment, such as hypoxaemia, airflow obstruction and vascular comorbidities. Figure 3 illustrates the potential impact of treatment on cognitive function and subsequent patient outcomes.

\section{Oxygen therapy}

Acute oxygen therapy has not been shown to improve neuropsychological performance [27, 90] and longer term oxygen therapy has either shown no benefit $[18,21]$ or modest cognitive improvement when administered for 6 months to hypoxaemic individuals, although much of the improvement was accounted for by practice effects $[9,15,91]$. Whilst oxygen therapy seems to reduce cognitive impairment, it may not prevent it completely. Some longitudinal studies have been performed $[6,9,47]$, but longer follow-up periods with larger, more diverse populations of COPD patients are required.

\section{Pulmonary rehabilitation/exercise}

A recent meta-analysis of randomised controlled trials of physical activity in the older general population showed that a $14 \%$ improvement in aerobic activity coincided with an improvement in cognitive capacity, mostly in motor function

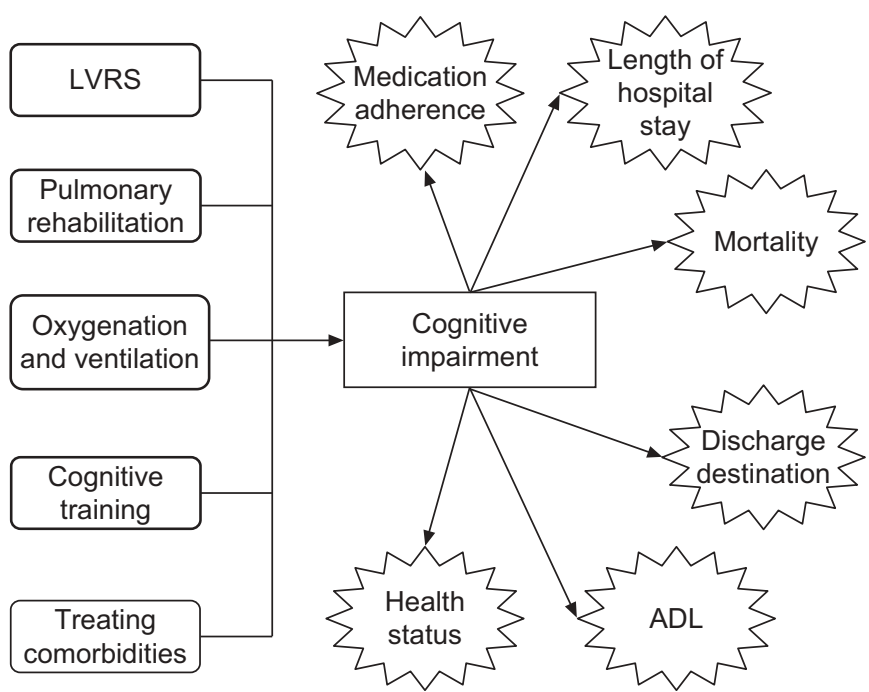

FIGURE 3. Possible treatments and outcomes of cognitive impairment in chronic obstructive pulmonary disease. LVRS: lung volume reduction surgery; ADL: activities of daily living.

and auditory attention, but also in processing speed and visual attention [92]. In COPD patients, evidence is limited, but suggests improvements in verbal fluency after 3 months [56]. It appears that appropriate exercise programmes may have beneficial effects on cognitive functions but it is unclear if these benefits are long term.

\section{Lung volume reduction surgery}

Lung volume reduction surgery has been associated with improvement in neuropsychological function as well as measures of depression, anxiety and quality of life over a follow-up period of 6 months [23], but there was no association between cognitive improvements and change in other variables. Even after adjustment for differences in exercise capacity and hypercapnia between the LVRS and control groups, improvement in psychomotor speed and verbal memory remained significant. However, the numbers in this study were small with a test group of only 19 subjects.

\section{Cognitive training}

A recent meta-analysis of nine randomised controlled trials assessing cognitive training in the early stages of Alzheimer's and vascular dementia show no evidence of improvement [93]. In COPD patients, cognitive training was not shown to be effective [94].

\section{Addressing comorbidities}

The impact on cognitive function of interventions to treat diabetes, hypertension, dyslipidaemia, and vitamin B12 and folate deficiencies has been the subject of several reviews. No benefit has been reported in terms of incidence of dementia or decline in cognitive function. Cognitive impairment was associated with poor response to antidepressant therapy [80].

\section{CONCLUSIONS}

Evidence of cognitive impairment in non-hypoxic individuals, together with a consistent pattern of cognitive deficit, suggests that COPD is associated with neuronal damage or dysfunction 
that is separate from other comorbidities, such as vascular disease. More work is required to validate methods of assessment, screening and treatment. Cognitive dysfunction may be associated with increased mortality and disability, but despite its potential importance, it remains a poorly understood comorbidity of COPD.

\section{STATEMENT OF INTEREST}

Statements of interest for J.W. Dodd and P.W. Jones can be found at www.erj.ersjournals.com/misc/statements.dtl

\section{REFERENCES}

1 Calverley PM. Neuropsychological deficits in chronic obstructive pulmonary disease. Monaldi Arch Chest Dis 1996; 51: 5-6.

2 Jones PW, Agusti AG. Outcomes and markers in the assessment of chronic obstructive pulmonary disease. Eur Respir J 2006; 27: 822-832.

3 Grant I, Heaton RK, McSweeny AJ, et al. Neuropsychologic findings in hypoxemic chronic obstructive pulmonary disease. Arch Intern Med 1982; 142: 1470-1476.

4 Incalzi RA, Corsonello A, Pedone C, et al. Construct validity of activities of daily living scale: a clue to distinguish the disabling effects of COPD and congestive heart failure. Chest 2005; 127: 830-838.

5 Fix AJ, Daughton D, Kass I, et al. Cognitive functioning and survival among patients with chronic obstructive pulmonary disease. Int J Neurosci 1985; 27: 13-17.

6 Antonelli-Incalzi C, Corsonello A, Pedone C, et al. Drawing impairment predicts mortality in severe COPD. Chest 2006; 130: 1687-1694

7 Lezak MD, Howieson DB, Loring DW, eds. Neuropsychological Assessment. 4th Edn. New York, Oxford University Press, 2004.

8 American Psychiatric Association Practice Guideline for the Treatment of Patients with Alzheimer's Disease and Other Dementias of later life. Arlington, American Psychiatric Association, 1997.

9 Heaton RK, Grant I, McSweeny AJ, et al. Psychologic effects of continuous and nocturnal oxygen therapy in hypoxemic chronic obstructive pulmonary disease. Arch Intern Med 1983; 143: 1941-1947.

10 Shim TS, Lee JH, Kim SY, et al. Cerebral metabolic abnormalities in COPD patients detected by localized proton magnetic resonance spectroscopy. Chest 2001; 120: 1506-1513.

11 Duong T, Acton PJ, Johnson RA, et al. The in vitro neuronal toxicity of pentraxins associated with Alzheimer's disease brain lesions. Brain Research 1998; 813: 303-312.

12 Warnberg J, Gomez-Martinez S, Romeo J, et al. Nutrition, inflammation, and cognitive function. Ann N Y Acad Sci 2009; 1153: 164-175.

13 Borson S, Scanlan J, Friedman S, et al. Modeling the impact of COPD on the brain. Int J Copd 2008; 3: 429-434.

14 Engelhart MJ, Geerlings MI, Meijer J, et al. Inflammatory proteins in plasma and the risk of dementia: the rotterdam study. Archives of Neurology 2004; 61: 668-72.

15 Krop HD, Block AJ, Cohen E. Neuropsychologic effects of continuous oxygen therapy in chronic obstructive pulmonary disease. Chest 1973; 64: 317-322.

16 Huppert FA. Memory impairment associated with chronic hypoxia. Thorax 1982; 37: 858-860.

17 Della SS, Donner CF, Sacco C, et al. Does chronic lung failure lead to cognitive failure? Schweizer Archiv fur Neurologie und Psychiatrie 1992; 143: 343-354.

18 Incalzi RA, Gemma A, Marra C, et al. Chronic obstructive pulmonary disease. An original model of cognitive decline. Am Rev Respir Dis 1993; 148: 418-424.
19 Incalzi RA, Gemma A, Marra C, et al. Verbal memory impairment in COPD: its mechanisms and clinical relevance. Chest 1997; 112 1506-1513.

20 Stuss DT, Peterkin I, Guzman DA, et al. Chronic obstructive pulmonary disease: effects of hypoxia on neurological and neuropsychological measures. J Clin Exp Neuropsychol 1997; 19: 515-524.

21 Hjalmarsen A, Waterloo K, Dahl A, et al. Effect of long-term oxygen therapy on cognitive and neurological dysfunction in chronic obstructive pulmonary disease. Eur Neurol 1999; 42: 27-35.

22 Antonelli-Incalzi C, Marra C, Giordano A, et al. Cognitive impairment in chronic obstructive pulmonary disease-a neuropsychological and spect study. J Neurol 2003; 250: 325-332.

23 Kozora E, Emery CF, Ellison MC, et al. Improved neurobehavioral functioning in emphysema patients following lung volume reduction surgery compared with medical therapy. Chest 2005, 128: 2653-2663.

24 Antonelli-Incalzi C, Corsonello A, Trojano L, et al. Screening of cognitive impairment in chronic obstructive pulmonary disease. Dement Geriatr Cogn Disord 2007; 23: 264-270.

25 Fix AJ, Golden CJ, Daughton D, et al. Neuropsychological deficits among patients with chronic obstructive pulmonary disease. Int $J$ Neurosci 1982; 16: 99-105.

26 Prigatano GP, Parsons O, Wright E, et al. Neuropsychological test performance in mildly hypoxemic patients with chronic obstructive pulmonary disease. J Consult Clin Psychol 1983; 51: 108-116.

27 Vos PJ, Folgering HT, van Herwaarden CL. Visual attention in patients with chronic obstructive pulmonary disease. Biol Psychol 1995; 41: 295-305.

28 Kozora E, Filley CM, Julian LJ, et al. Cognitive functioning in patients with chronic obstructive pulmonary disease and mild hypoxemia compared with patients with mild Alzheimer disease and normal controls. Neuropsychiatry Neuropsychol Behav Neurol 1999; 12: 178-183.

29 Liesker JJ, Postma DS, Beukema RJ, et al. Cognitive performance in patients with COPD. Respir Med 2004; 98: 351-356.

30 Favalli A, Miozzo A, Cossi S, et al. Differences in neuropsychological profile between healthy and COPD older persons. Int $J$ Geriatr Psychiatry 2008; 23: 220-221.

31 Grant I, Prigatano GP, Heaton RK, et al. Progressive neuropsychologic impairment and hypoxemia. Relationship in chronic obstructive pulmonary disease. Arch Gen Psychiatry 1987; 44: 999-1006.

32 Hung W, Wisnivesky JP, Siu AL, et al. Cognitive decline among patients with chronic obstructive pulmonary disease. Am J Respir Crit Care Med 2009; 180: 134-137.

33 Isoaho $\mathrm{R}$, Puolijoki $\mathrm{H}$, Huhti $\mathrm{E}$, et al. Chronic obstructive pulmonary disease and cognitive impairment in the elderly. Int Psychogeriatr 1996; 8: 113-125.

34 Cook NR, Albert MS, Berkman LF, et al. Interrelationships of peak expiratory flow rate with physical and cognitive function in the elderly: MacArthur Foundation studies of aging. J Gerontol A Bio Sci Med Sci 1995; 50: M317-M323.

35 Albert MS, Jones K, Savage CR, et al. Predictors of cognitive change in older persons: MacArthur studies of successful aging. Psychol Aging 1995; 10: 578-589.

36 Chyou PH, White LR, Yano K, et al. Pulmonary function measures as predictors and correlates of cognitive functioning in later life. Am J Epidemiol 1996; 143: 750-756.

37 Cerhan JR, Folsom AR, Mortimer JA, et al. Correlates of cognitive function in middle-aged adults. Atherosclerosis Risk in Communities (ARIC) Study Investigators. Gerontology 1998; 44: 95-105.

38 Emery CF, Pedersen NL, Svartengren M, et al. Longitudinal and genetic effects in the relationship between pulmonary function and cognitive performance. J Gerontol B Psychol Sci Soc Sci 1998; 53: 311-317. 
39 Anstey KJ, Windsor TD, Jorm AF, et al. Association of pulmonary function with cognitive performance in early, middle and late adulthood. Gerontology 2004; 50: 230-234.

40 Aleman A, Muller M, de Haan EH, et al. Vascular risk factors and cognitive function in a sample of independently living men. Neurobiol Aging 2005; 26: 485-490.

41 Sachdev PS, Anstey KJ, Parslow RA, et al. Pulmonary function, cognitive impairment and brain atrophy in a middle-aged community sample. Dement Geriatr Cogn Disord 2006; 21: 300-308.

42 Allaire JC, Tamez E, Whitfield KE. Examining the association between lung functioning and cognitive performance in African American adults. J Aging Health 2007; 19: 106-122.

43 Incalzi RA, Chiappini F, Fuso L, et al. Predicting cognitive decline in patients with hypoxaemic COPD. Respir Med 1998; 92: 527-533.

44 Etnier J, Johnston R, Dagenbach D, et al. The relationships among pulmonary function, aerobic fitness, and cognitive functioning in older COPD patients. Chest 1999; 116: 953-960.

45 Antonelli-Incalzi C, Imperiale C, Bellia V, et al. Do GOLD stages of COPD severity really correspond to differences in health status? Eur Respir J 2003; 22: 444-449.

46 Ohrui $\mathrm{T}$, Tanaka $\mathrm{K}$, Chiba $\mathrm{K}$, et al. Cognitive decline in patients with long-term domiciliary oxygen therapy. Tohoku J Exp Med 2005; 206: 347-352.

47 Parekh PI, Blumenthal JA, Babyak MA, et al. Gas exchange and exercise capacity affect neurocognitive performance in patients with lung disease. Psychosom Med 2005; 67: 425-432.

48 Ranieri P, Bianchetti A, Margiotta A, et al. Predictors of 6-month mortality in elderly patients with mild chronic obstructive pulmonary disease discharged from a medical ward after acute nonacidotic exacerbation. J Am Geriatr Soc 2008; 56: 909-913.

49 Ambrosino N, Bruletti G, Scala V, et al. Cognitive and perceived health status in patient with chronic obstructive pulmonary disease surviving acute on chronic respiratory failure: a controlled study. Intensive Care Med 2002; 28: 170-177.

50 Polich J. P300 clinical utility and control of variability. J Clin Neurophysiol 1998; 15: 14-33.

51 Kirkil G, Tug T, Ozel E, et al. The evaluation of cognitive functions with P300 test for chronic obstructive pulmonary disease patients in attack and stable period. Clin Neurol Neurosurg 2007; 109: 553-560.

52 Emery CF. Effects of age on physiological and psychological functioning among COPD patients in an exercise program. J Aging Health 1994; 6: 3-16.

53 Emery CF, Schein RL, Hauck ER, et al. Psychological and cognitive outcomes of a randomized trial of exercise among patients with chronic obstructive pulmonary disease. Health Psychology 1998; 17: 232-240.

54 Emery CF, Honn VJ, Frid DJ, et al. Acute effects of exercise on cognition in patients with chronic obstructive pulmonary disease. Am J Respir Crit Care Med 2001; 164: 1624-1627.

55 Emery CF, Shermer RL, Hauck ER, et al. Cognitive and psychological outcomes of exercise in a 1-year follow-up study of patients with chronic obstructive pulmonary disease. Health Psychology 2003; 22: 598-604.

56 Etnier JL, Berry M. Fluid intelligence in an older COPD sample after short- or long-term exercise. Med Sci Sports Exerc 2001; 33: $1620-1628$

57 Emery CF, Leatherman NE, Burker EJ, et al. Psychological outcomes of a pulmonary rehabilitation program. Chest 1991; 100: 613-617.

58 Kozora E, Tran ZV, Make B. Neurobehavioral improvement after brief rehabilitation in patients with chronic obstructive pulmonary disease. J Cardiopulm Rehabil 2002; 22: 426-430.

59 Kuo HK, Jones RN, Milberg WP, et al. Effect of blood pressure and diabetes mellitus on cognitive and physical functions in older adults: a longitudinal analysis of the advanced cognitive training for independent and vital elderly cohort. J Am Geriatr Soc 2005; 53 $1154-1161$.
60 Report of the National Chronic Obstructive Pulmonary Disease Audit 2008: clinical audit of COPD exacerbations admitte to acute NHS units across the UK. Royal College of Physicians London British Thoracic Society, British Lung Foundation. 2008 Available from: www.rcplondon.ac.uk/clinical-standards/ceeu/ Current-work/ncrop/Documents/Report-of-The-National-COPDAudit-2008-clinical-audit-of-COPD-exacerbations-admitted-toacute-NHS-units-across-the-UK.pdf

61 Fioravanti M, Nacca D, Amati S, et al. Chronic obstructive pulmonary disease and associated patterns of memory decline. Dementia 1995; 6: 39-48.

62 Anstey KJ, von SC, Salim A, et al. Smoking as a risk factor for dementia and cognitive decline: a meta-analysis of prospective studies. Am J Epidemiol 2007; 166: 367-378.

63 Swan GE, Lessov-Schlaggar CN. The effects of tobacco smoke and nicotine on cognition and the brain. Neuropsychol Rev 2007; 17: 259-273.

64 Ott A, Andersen K, Dewey ME, et al. Effect of smoking on global cognitive function in nondemented elderly. Neurology 2004; 62 920-924.

65 Richards M, Strachan D, Hardy R, et al. Lung function and cognitive ability in a longitudinal birth cohort study. Psychosom Med 2005; 67: 602-608.

66 Walker MP. Sleep-dependent memory processing. Har Rev Psychiatry 2008; 16: 287-298.

67 Urbano F, Mohsenin V. Chronic obstructive pulmonary disease and sleep: the interaction. Panminerva Medica 2006; 48: 223-230.

68 Fletcher EC. Chronic lung disease in the sleep apnea syndrome. Lung 1990; 168: Suppl., 751-761.

69 Alam I, Lewis K, Stephens JW, et al. Obesity, metabolic syndrome and sleep apnoea: all pro-inflammatory states. Obesity Rev 2007; 8 119-127.

70 Engleman HM, Douglas NJ. Sleep. 4: Sleepiness, cognitive function, and quality of life in obstructive sleep apnoea/ hypopnoea syndrome. Thorax 2004; 59: 618-622.

71 Beebe DW, Groesz L, Wells C, et al. The neuropsychological effects of obstructive sleep apnea: a meta-analysis of norm-referenced and case-controlled data. Sleep 2003; 26: 298-307.

72 Martin SE, Engleman HM, Deary IJ, et al. The effect of sleep fragmentation on daytime function. Am J Respir Critical Care Med 1996; 153: 1328-1332.

73 Roehrs T, Merrion M, Pedrosi B, et al. Neuropsychological function in obstructive sleep apnea syndrome (OSAS) compared to chronic obstructive pulmonary disease (COPD). Sleep 1995; 18: 382-388.

74 Antonelli-Incalzi C, Marra C, Salvigni BL, et al. Does cognitive dysfunction conform to a distinctive pattern in obstructive sleep apnea syndrome? J Sleep Res 2004; 13: 79-86.

75 Breslin E, van der Schans C, Breukink S, et al. Perception of fatigue and quality of life in patients with COPD. Chest 1998; 114: 958-964.

76 van EL, Yzermans CJ, Brouwer HJ. Prevalence of depression in patients with chronic obstructive pulmonary disease: a systematic review. Thorax 1999; 54: 688-692.

77 Hynninen KM, Breitve MH, Wiborg AB, et al. Psychological characteristics of patients with chronic obstructive pulmonary disease: a review. J Psychosom Res 2005; 59: 429-443.

78 Aydin IO, Ulusahin A. Depression, anxiety comorbidity, and disability in tuberculosis and chronic obstructive pulmonary disease patients: applicability of GHQ-12. Gen Hosp Psychiatry 2001; 23: 77-83.

79 Kozora E, Emery C, Kaplan RM, et al. Cognitive and psychological issues in emphysema. Proc Am Thorac Soc 2008; 5: 556-560.

80 Potter GG, Steffens DC. Contribution of depression to cognitive impairment and dementia in older adults. Neurologist 2007; 13 105-117.

81 Campbell SE, Seymour DG, Primrose WR, et al. A systematic literature review of factors affecting outcome in older medical patients admitted to hospital. Age Ageing 2004; 33: 110-115. 
82 Artero S, Touchon J, Ritchie K. Disability and mild cognitive impairment: a longitudinal population-based study. Int J Geriatric Psychiatry 2001; 16: 1092-1097.

83 Allaire JC, Gamaldo A, Ayotte BJ, et al. Mild cognitive impairment and objective instrumental everyday functioning: the everyday cognition battery memory test. J Am Geriatr Soc 2009; 57: 120-125.

84 Allen SC, Jain M, Ragab S, et al. Acquisition and short-term retention of inhaler techniques require intact executive function in elderly subjects. Age Ageing 2003; 32: 299-302.

85 Antonelli-Incalzi RA, Pedone C, Onder G, et al. Predicting length of stay of older patients with exacerbated chronic obstructive pulmonary disease. Aging (Milano) 2001; 13: 49-57.

86 Antonelli-Incalzi C, Corsonello A, Trojano L, et al. Correlation between cognitive impairment and dependence in hypoxemic COPD. J Clin Exp Neuropsychol 2008; 30: 141-150.

87 Incalzi RA, Chiappini F, Fuso L, et al. Predicting cognitive decline in patients with hypoxaemic COPD. Respir Med 1998; 92: 527-533.

88 Conte ME, Pedone C, Forastiere F, et al. Discriminative and predictive properties of disease-specific and generic health status indexes in elderly COPD patients. BMC Pulm Med 2008; 8: 14.
89 Salik Y, Ozalevli S, Cimrin AH. Cognitive function and its effects on the quality of life status in the patients with chronic obstructive pulmonary disease (COPD). Arch Gerontol Geriatr 2007; 45: 273-280.

90 Wilson DK, Kaplan RM, Timms RM, et al. Acute effects of oxygen treatment upon information processing in hypoxemic COPD patients. Chest 1985; 88: 239-243.

91 Borak J, Sliwinski P, Tobiasz M, et al. Psychological status of COPD patients before and after one year of long-term oxygen therapy. Monaldi Arch Chest Dis 1996; 51: 7-11.

92 Angevaren M, Aufdemkampe G, Verhaar HJ, et al. Physical activity and enhanced fitness to improve cognitive function in older people without known cognitive impairment. Cochrane Database Syst Rev 2008; 2: CD005381.

93 Clare L, Woods RT, Moniz Cook ED, et al. Cognitive rehabilitation and cognitive training for early-stage Alzheimer's disease and vascular dementia. Cochrane Database of Syst Rev 2003; 4: CD003260.

94 Incalzi RA, Corsonello A, Trojano L, et al. Cognitive training is ineffective in hypoxemic COPD: a six-month randomized controlled trial. Rejuvenation Res 2008; 11: 239-250. 